\title{
Influence of Dietary Chitosan Feeding Duration on Glucose and Lipid Metabolism in a Diabetic Rat Model
}

\author{
Shing-Hwa Liu ${ }^{1,2,3} \mathbb{\infty}$, Shih-An Feng ${ }^{4}$, Chen-Yuan Chiu ${ }^{5}\left(\mathbb{D}\right.$ and Meng-Tsan Chiang ${ }^{4, *}$ \\ 1 Graduate Institute of Toxicology, College of Medicine, National Taiwan University, Taipei 10051, Taiwan; \\ shinghwaliu@ntu.edu.tw \\ 2 Department of Medical Research, China Medical University Hospital, China Medical University, \\ Taichung 40402, Taiwan \\ 3 Department of Pediatrics, College of Medicine, National Taiwan University Hospital, Taipei 10051, Taiwan \\ 4 Department of Food Science, National Taiwan Ocean University, Keelung 20224, Taiwan; \\ afrankgod@gmail.com \\ 5 Center of Consultation, Center for Drug Evaluation, Taipei 115, Taiwan; kidchiou@gmail.com \\ * Correspondence: a0071@mail.ntou.edu.tw
}

check for

updates

Citation: Liu, S.-H.; Feng, S.-A.; Chiu, C.-Y.; Chiang, M.-T. Influence of Dietary Chitosan Feeding Duration on Glucose and Lipid Metabolism in a Diabetic Rat Model. Molecules 2021, 26, 5033. https://doi.org/10.3390/ molecules26165033

Academic Editors: Tzu-Ming Pan, Chun-Lin Lee and Monica

Rosa Loizzo

Received: 30 June 2021

Accepted: 17 August 2021

Published: 19 August 2021

Publisher's Note: MDPI stays neutral with regard to jurisdictional claims in published maps and institutional affiliations.

Copyright: (c) 2021 by the authors. Licensee MDPI, Basel, Switzerland. This article is an open access article distributed under the terms and conditions of the Creative Commons Attribution (CC BY) license (https:/ / creativecommons.org/licenses/by/ $4.0 /)$.

\begin{abstract}
This study was designed to investigate the influence of dietary chitosan feeding-duration on glucose and lipid metabolism in diabetic rats induced by streptozotocin and nicotinamide [a non-insulin-dependent diabetes mellitus (NIDDM) model]. Male Sprague-Dawley rats were used as experimental animals and divided into short-term (6 weeks) and long-term (11 weeks) feeding durations, and each duration contained five groups: (1) control, (2) control $+5 \%$ chitosan, (3) diabetes, (4) diabetes $+0.8 \mathrm{mg} / \mathrm{kg}$ rosiglitazone (a positive control), and (5) diabetes $+5 \%$ chitosan. Whether the chitosan feeding was for 6 or 11 weeks, the chitosan supplementation decreased blood glucose and lipids levels and liver lipid accumulation. However, chitosan supplementation decreased plasma tumor necrosis factor (TNF)- $\alpha$, insulin levels, alanine aminotransferase (ALT) activity, insulin resistance (HOMA-IR), and adipose tissue lipoprotein lipase activity. Meanwhile, it increased plasma high-density lipoproteins (HDL)-cholesterol level, plasma angiopoietin-like-4 protein expression, and plasma triglyceride levels (at 11-week feeding duration only). Taken together, 11-week (longterm) chitosan feeding may help to ameliorate the glucose and lipid metabolism in a NIDDM diabetic rat model.
\end{abstract}

Keywords: chitosan; diabetes; glucose and lipid metabolism

\section{Introduction}

Diabetes mellitus (DM) is a global chronic metabolic disease. More than $90 \%$ of diabetic patients suffer from type 2 DM (non-insulin-dependent DM; NIDDM) [1]. Type $2 \mathrm{DM}$ is mostly associated with obesity and insulin resistance and may increase the risk of chronic complications such as retinopathy, nephropathy, cardiovascular diseases, and neuropathy [1,2]. Moreover, obesity refers to an excessive amount of adipose tissue, which is an important endocrine organ that secretes adipocytokines such as tumor necrosis factor-alpha (TNF- $\alpha$ ), which can enhance insulin resistance and atherosclerosis in diabetic patients [3,4].

Dietary fibers are suggested to have beneficial effects on the plasma lipids of patients with diabetes and atherosclerosis. Chitosan is a dietary fiber produced by the deacetylation of chitin. Its chemical structure is similar to cellulose, linked by $\beta(1 \rightarrow 4)$ glycosidic linkage, and is not digested by mammalian digestive enzymes [5]. Chitosan is generally known for its plasma cholesterol-lowering effects due to increased fecal fat excretions [6,7]. The previous studies have also demonstrated that chitosan decreases plasma glucose concentrations through a decrease in liver gluconeogenesis and an increase in skeletal muscle glucose uptake and utilization [8], as well as a reduction in intestinal disaccharidase 
activity [9] in a streptozotocin (STZ)-induced diabetic rat model. In addition, chitosan has also been shown to reduce plasma TNF- $\alpha$ and adipose weight in the animal models fed a high-fat diet or a cholesterol-enriched diet $[10,11]$. However, there is little information concerning the hypolipidemic and hypoglycemic effects of chitosan in type 2 diabetes with obesity. Guo et al. (2020) have reported that the blood glucose level of patients with diabetes and obesity / overweight can be improved by supplementation with chitosan for at least 13 weeks [12]. Our previous study revealed that 7-week chitosan feeding did not affect blood glucose level but did decrease HOMA-IR index [13]. These findings indicate that the effects of chitosan on blood glucose and cholesterol concentrations in type 2 diabetes still remain to be clarified. On the other hand, the effectiveness of chitosan on glucose and lipid metabolism for long-term or short-term use is still inconclusive.

STZ can selectively damage the pancreatic $\beta$-cells and develop hypoinsulinemia and hyperglycemia, similar to the type 1 DM condition [14]. Pretreatment of nicotinamide can scavenge free radicals and recruit the consumption of nicotinamide adenine dinucleotide $\left(\mathrm{NAD}^{+}\right)$in pancreatic $\beta$-cells after STZ injection. Hence, the injection of nicotinamide can partially protect the pancreatic $\beta$-cells after STZ injection and then develop a NIDDM model with mild hyperglycemia and insulin resistance [14].

The present study was to investigate the influence of dietary chitosan $[5 \%$ high molecular weight (MW) chitosan] feeding duration on glucose and lipid metabolism in a NIDDM rat model induced by streptozotocin and nicotinamide.

\section{Results}

\subsection{Effects of Chitosan on Body Weight, Food Intake, Feed Efficiency, and Organ and Tissue Weights in Diabetic Rats with Different Feeding Duration}

First, we tested the influence of chitosan feeding duration on body weight, food intake, feed efficiency, and organ/tissue weights in diabetic rats. After both 6 and 11 weeks of being fed different diets, there were no significant differences in body weight, food intake, and feed efficiency among the groups [control (C), 5\% high MW chitosan (CS), diabetes (DM), DM + thiazolidinediones (TZD-rosiglitazone; a positive control), and DM + CS; Table 1].

Table 1. The changes of body weight and food intake in SD rats fed different experimental diets for 6 and 11 weeks.

\begin{tabular}{cccccc}
\hline Diet & C & CS & DM & DM + TZD & DM + CS \\
\hline 6 weeks & & & & & \\
Initial body weight (g) & $366.7 \pm 15.9$ & $366.7 \pm 71.8$ & $382.5 \pm 14.0$ & $382.1 \pm 27.4$ & $385.1 \pm 28.4$ \\
Final body weight (g) & $489.0 \pm 28.2$ & $504.1 \pm 69.6$ & $523.8 \pm 44.1$ & $526.8 \pm 41.0$ & $524.5 \pm 52.4$ \\
Bodyweight gain (g) & $122.3 \pm 24.0$ & $137.4 \pm 49.4$ & $141.3 \pm 31.7$ & $144.7 \pm 24.1$ & $139.4 \pm 27.8$ \\
Food intake (g/day) & $24.1 \pm 2.1$ & $25.5 \pm 3.3$ & $27.2 \pm 5.6$ & $24.5 \pm 4.0$ & $23.3 \pm 2.4$ \\
Feed efficiency (\%) & $4.7 \pm 0.64$ & $4.7 \pm 1.9$ & $4.8 \pm 1.2$ & $5.4 \pm 1.2$ & $5.6 \pm 1.0$ \\
11 weeks & & & & & \\
Initial body weight (g) & $369.8 \pm 26.7$ & $368.9 \pm 24.6$ & $382.1 \pm 16.9$ & $382.7 \pm 18.7$ & $383.0 \pm 17.8$ \\
Final body weight (g) & $536.9 \pm 37.3$ & $523.8 \pm 30.7$ & $555.3 \pm 49.9$ & $522.0 \pm 40.4$ & $529.0 \pm 31.2$ \\
Bodyweight gain (g) & $170.9 \pm 22.9$ & $158.9 \pm 29.4$ & $174.2 \pm 34.6$ & $143.4 \pm 29.9$ & $149.2 \pm 26.8$ \\
Food intake (g/day) & $24.9 \pm 1.5$ & $24.3 \pm 1.9$ & $26.5 \pm 2.5$ & $25.6 \pm 2.2$ & $25.6 \pm 2.7$ \\
Feed efficiency (\%) & $6.9 \pm 0.87$ & $6.7 \pm 1.3$ & $6.8 \pm 1.7$ & $5.6 \pm 0.9$ & $6.0 \pm 1.0$ \\
\hline
\end{tabular}

Results are expressed as mean \pm SD for each group $(n=8)$. Feed efficiency $=[$ weight gain $(\mathrm{g}) /$ food intake $(\mathrm{g})] \times 100 \%$. C: control diet; CS: control diet $+5 \%$ high molecular weight chitosan; DM: diabetes + control diet; DM + TZD: diabetes + control diet $+0.8 \mathrm{mg} / \mathrm{kg}$ thiazolidinediones (rosiglitazone); DM + CS: diabetes + control diet $+5 \%$ high molecular weight chitosan .

The liver weight/relative liver weight and adipose tissue weight/relative adipose tissue weight were not changed in diabetic rats (DM group) at 6-week feeding duration, but they were significantly increased at 11-week feeding duration, which could be significantly reversed by administration of both chitosan and TZD (Table 2). There was a significant decrease in liver weight/relative liver weight in the CS (versus C), DM + TZD, and DM + CS (versus DM) groups at both 6- and 11-week feeding duration (Table 2). A significant decrease in perirenal fat weight was also observed in the DM + CS group compared to the 
DM group at both 6- and 11-week feeding durations (Table 2). Compared to the C group, there were significant decreases in liver weight, perirenal fat, and relative weight in the CS group at both 6- and 11-week feeding durations (Table 2).

Table 2. The changes of tissue/organ weights in SD rats fed different experimental diets for 6 and 11 weeks.

\begin{tabular}{|c|c|c|c|c|c|}
\hline Diet & $\mathrm{C}$ & CS & DM & $\mathrm{DM}+\mathrm{TZD}$ & $\mathrm{DM}+\mathrm{CS}$ \\
\hline \multicolumn{6}{|l|}{6 weeks } \\
\hline Liver weight (g) & $23.4 \pm 2.5$ & $19.8 \pm 3.3 *$ & $26.8 \pm 4.1$ & $22.8 \pm 2.7 \#$ & $21.6 \pm 3.7 \#$ \\
\hline Relative liver weight (g/100 g BW) & $4.9 \pm 0.42$ & $4.1 \pm 0.44 *$ & $5.2 \pm 0.70$ & $4.4 \pm 0.42 \#$ & $4.2 \pm 0.39 \#$ \\
\hline Perirenal fat (g) & $15.9 \pm 3.1$ & $12.5 \pm 2.7 *$ & $16.7 \pm 3.2$ & $14.1 \pm 2.3$ & $12.3 \pm 3.8 \#$ \\
\hline Relative perirenal fat weight (g/100 g BW) & $3.6 \pm 0.74$ & $2.6 \pm 0.46^{*}$ & $3.3 \pm 0.60$ & $2.8 \pm 0.5$ & $2.4 \pm 0.50 \#$ \\
\hline Epididymal fat $(\mathrm{g})$ & $9.5 \pm 2.9$ & $8.8 \pm 2.7$ & $9.9 \pm 2.4$ & $8.8 \pm 1.3$ & $9.0 \pm 3.0$ \\
\hline Total adipose tissue weight $(\mathrm{g})$ & $25.4 \pm 5.0$ & $21.3 \pm 4.6$ & $26.7 \pm 4.9$ & $22.9 \pm 3.1$ & $21.3 \pm 6.7$ \\
\hline $\begin{array}{l}\text { Relative adipose tissue weight (g/100 g BW) } \\
\qquad \mathbf{1 1} \text { weeks }\end{array}$ & $5.3 \pm 1.0$ & $4.4 \pm 0.77$ & $5.2 \pm 0.80$ & $4.5 \pm 0.69$ & $4.1 \pm 0.88 \#$ \\
\hline Liver weight (g) & $28.2 \pm 3.5$ & $23.1 \pm 3.0 *$ & $32.7 \pm 3.4$ * & $25.3 \pm 3.1 \#$ & $23.1 \pm 3.1 \#$ \\
\hline Relative liver weight (g/100 g BW) & $5.3 \pm 0.5$ & $4.4 \pm 0.49 *$ & $5.9 \pm 0.47 *$ & $5.0 \pm 0.94 \#$ & $4.4 \pm 0.43 \#$ \\
\hline Perirenal fat $(\mathrm{g})$ & $14.9 \pm 3.4$ & $11.3 \pm 3.0 *$ & $18.3 \pm 2.9 *$ & $13.2 \pm 4.2 \#$ & $11.9 \pm 3.7 \#$ \\
\hline Relative perirenal fat weight (g/100 g BW) & $2.8 \pm 0.6$ & $2.2 \pm 0.6$ & $3.3 \pm 0.37$ & $2.6 \pm 0.80 \#$ & $2.3 \pm 0.71 \#$ \\
\hline Epididymal fat $(\mathrm{g})$ & $9.0 \pm 3.4$ & $8.7 \pm 3.6$ & $11.7 \pm 1.8$ & $9.0 \pm 1.9 \#$ & $7.4 \pm 1.5 \#$ \\
\hline Total adipose tissue weight $(\mathrm{g})$ & $23.9 \pm 5.5$ & $20.1 \pm 6.1$ & $30.1 \pm 4.3$ * & $22.2 \pm 6.0 \#$ & $19.3 \pm 5.1 \#$ \\
\hline Relative adipose tissue weight (g/100 g BW) & $4.4 \pm 0.87$ & $3.8 \pm 1.1$ & $5.4 \pm 0.59$ * & $4.3 \pm 1.2 \#$ & $3.7 \pm 1.0 \#$ \\
\hline
\end{tabular}

Results are expressed as mean \pm SD for each group $(n=8)$. The significant difference $(p<0.05)$ was analyzed by one-way ANOVA and two-tailed Student's $t$-test. *: versus C; \#: versus DM. C: control diet; CS: control diet $+5 \%$ high molecular weight chitosan; DM: diabetes + control diet; DM + TZD: diabetes + control diet $+0.8 \mathrm{mg} / \mathrm{kg}$ thiazolidinediones (rosiglitazone); DM + CS: diabetes + control diet $+5 \%$ high molecular weight chitosan.

\subsection{Effects of Chitosan on Plasma Biochemical Markers and Lipids in Diabetic Rats with Different Feeding Duration}

We next examined the influence of chitosan feeding duration on plasma biochemical markers and lipids in diabetic rats. As shown in Table 3, the plasma glucose levels were significantly increased in the DM group at both 6- and 11-week feeding durations, which could be significantly reversed by TZD treatment and chitosan supplementation. For the 6-week feeding duration, there were no significant differences for TNF- $\alpha$ and insulin levels among all groups; except for the DM + TZD group (versus DM), there were no differences among the other groups for the homeostasis model assessment equation-insulin resistance (HOMA-IR) (Table 3). However, there were significant decreases in TNF- $\alpha$, insulin, and HOMA-IR in the DM + TZD and DM + CS groups (versus DM) at 11-week feeding duration (Table 3). The significant decreases in the TNF- $\alpha$ and insulin levels were also observed in the CS group compared to the $C$ group at 11-week feeding duration only (Table 3). There were significant decreases in plasma ALT and AST activities in DM + TZD and DM + CS groups at 11-week feeding duration compared to the DM group (Table 3). Moreover, plasma ALT activity was significantly decreased in the CS group (versus C group) at the 11-week duration (Table 3). The significant difference between DM + TZD and DM + CS groups for AST activity (at 6-week feeding duration) and TNF- $\alpha$ level (at 11-week feeding duration) was also observed (Table 3). 
Table 3. The changes of plasma AST, ALT, Glucose, insulin concentration, and HOMA-IR index in SD rats fed different experimental diets for 6 and 11 weeks.

\begin{tabular}{|c|c|c|c|c|c|}
\hline Diet & $\mathrm{C}$ & CS & DM & DM + TZD & $\mathrm{DM}+\mathrm{CS}$ \\
\hline \multicolumn{6}{|l|}{6 weeks } \\
\hline AST (U/L) & $121.9 \pm 49.8$ & $112.8 \pm 40.1$ & $178.5 \pm 36.3^{*}$ & $171.8 \pm 59.4$ & $108.0 \pm 49.8$ \#@ \\
\hline $\operatorname{ALT}(\mathrm{U} / \mathrm{L})$ & $30.4 \pm 25.9$ & $23.2 \pm 13.1$ & $34.6 \pm 12.6$ & $28.2 \pm 13.7$ & $28.8 \pm 10.9$ \\
\hline $\mathrm{TNF}-\alpha(\mathrm{pg} / \mathrm{mL})$ & $31.3 \pm 10.7$ & $31.7 \pm 10.3$ & $42.3 \pm 19.9$ & $37.8 \pm 20.2$ & $37.4 \pm 17.0$ \\
\hline Glucose (mg/dL) & $190.5 \pm 12.2$ & $198.3 \pm 11.7$ & $241.6 \pm 32.9 *$ & $200.1 \pm 24.8 \#$ & $203.2 \pm 26.5 \#$ \\
\hline Insulin $(\mu \mathrm{g} / \mathrm{L})$ & $0.94 \pm 0.25$ & $0.86 \pm 0.31$ & $0.88 \pm 0.17$ & $0.71 \pm 0.30$ & $0.8 \pm 0.19$ \\
\hline HOMA-IR & $9.8 \pm 2.4$ & $9.5 \pm 3.8$ & $11.9 \pm 3.3$ & $8.0 \pm 3.6 \#$ & $9.3 \pm 2.2$ \\
\hline \multicolumn{6}{|l|}{11 weeks } \\
\hline AST (U/L) & $96.94 \pm 60.69$ & $101.7 \pm 51.5$ & $205.1 \pm 90.45$ * & $98.2 \pm 56.1 \#$ & $89.7 \pm 52.1 \#$ \\
\hline $\operatorname{ALT}(\mathrm{U} / \mathrm{L})$ & $30.1 \pm 19.8$ & $20.4 \pm 4.1 *$ & $48.2 \pm 29.4$ & $15.8 \pm 4.8 \#$ & $20.5 \pm 13.1 \#$ \\
\hline $\mathrm{TNF}-\alpha(\mathrm{pg} / \mathrm{mL})$ & $38.8 \pm 9.7$ & $24.0 \pm 10.3$ * & $66.6 \pm 24.2 *$ & $18.7 \pm 5.0$ *\# & $28.1 \pm 9.5 \# @$ \\
\hline Glucose (mg/dL) & $210.7 \pm 32.77$ & $218.2 \pm 9.44$ & $236.8 \pm 14.75 *$ & $206.5 \pm 13.55 \#$ & $215.6 \pm 11.4 \#$ \\
\hline Insulin $(\mu \mathrm{g} / \mathrm{L})$ & $1.1 \pm 0.35$ & $0.79 \pm 0.13$ * & $0.92 \pm 0.10$ & $0.77 \pm 0.12 \#$ & $0.76 \pm 0.14 \#$ \\
\hline HOMA-IR & $13.6 \pm 5.5$ & $9.6 \pm 1.9$ & $12.1 \pm 1.2$ & $9.3 \pm 2.1 \#$ & $9.1 \pm 2.1 \#$ \\
\hline
\end{tabular}

Results are expressed as mean \pm SD for each group $(n=8)$. The significant difference $(p<0.05)$ was analyzed by one-way ANOVA and two-tailed Student's $t$-test. *: versus C; \#: versus DM; @: versus DM + TZD. C: control diet; CS: control diet + 5\% high molecular weight chitosan; DM: diabetes + control diet; DM + TZD: diabetes + control diet $+0.8 \mathrm{mg} / \mathrm{kg}$ thiazolidinediones (rosiglitazone); $\mathrm{DM}+\mathrm{CS}$ : diabetes + control diet $+5 \%$ high molecular weight chitosan .

Moreover, the significant reductions in the levels of the LDL-C, LDL-C + VLDL-C, and HDL-C/ LDL-C + VLDL-C ratios were shown in CS (versus C) and DM + CS (versus $\mathrm{DM}$ ) groups at both 6- and 11-week feeding duration; but there were significant decreases in the levels of total cholesterol and atherogenic index and the significant increase in the levels of HDL-C and triglyceride in CS (versus C) and DM + CS (versus DM) groups at 11-week feeding duration only (Table 4). The levels of VLDL-C were also decreased in the DM + TZD group (versus DM) at the 11-week feeding duration (Table 4). A significant decrease in the atherogenic index was also shown in the DM + TZD group compared to the DM group at the 11-week feeding duration (Table 4). There was also a decrease in the TC/HDL-C ratio between CS and C groups and a decrease in VLDL-C levels between the DM + TZD and DM groups at a 6-week feeding duration (Table 4). The significant decreases in both total cholesterol and VLDL levels were shown in the DM + CS group compared to the CS group at the 6-week feeding duration (Table 4). There were significant differences between the DM + TZD and DM + CS groups for LDL-C and VLDL-C levels at 6-week feeding duration, and LDL-C and Triglyceride levels and atherogenic index at 11-week feeding duration (Table 4).

\subsection{Effects of Chitosan on Hepatic and Fecal Lipid Responses in Diabetic Rats with Different Feeding Duration}

We next investigated the influence of chitosan feeding duration on hepatic and fecal lipid responses in diabetic rats. As shown in Table 5, there were significant reductions in the levels of liver total cholesterol in the CS (versus C) and DM + CS (versus DM) groups at both 6- and 11-week feeding durations. However, in the DM + TZD group, only the 11-week feeding duration showed a significant decrease in the liver triglyceride levels compared to the DM group. There was a significant decrease in liver total cholesterol levels in the DM + CS group compared to the DM + TZD group on an 11-week feeding duration (Table 5). 
Table 4. The changes of plasma lipids concentration in SD rats fed different experimental diets after 6 and 11 weeks.

\begin{tabular}{|c|c|c|c|c|c|}
\hline Diet & $\mathrm{C}$ & CS & DM & $\mathrm{DM}+\mathrm{TZD}$ & $\mathrm{DM}+\mathrm{CS}$ \\
\hline \multicolumn{6}{|l|}{6 weeks } \\
\hline Total cholesterol (mg/dL) & $114.8 \pm 24.8$ & $98.9 \pm 19.5$ & $97.5 \pm 17.2$ & $79.5 \pm 23.7$ & $81.5 \pm 10.5 \# \&$ \\
\hline HDL-C (mg/dL) & $40.1 \pm 10.9$ & $45.3 \pm 12.7$ & $32.5 \pm 10.5$ & $33.0 \pm 12.2$ & $40.7 \pm 12.9$ \\
\hline LDL-C (mg/dL) & $40.2 \pm 15.4$ & $15.3 \pm 8.5^{*}$ & $40.1 \pm 29.4$ & $31.9 \pm 15.2$ & $13.7 \pm 14.4$ \#@ \\
\hline VLDL-C (mg/dL) & $34.5 \pm 9.1$ & $38.3 \pm 5.8$ & $24.9 \pm 6.7$ & $14.6 \pm 11.5 \#$ & $27.1 \pm 10.9 \& @$ \\
\hline LDL-C + VLDL-C & $74.7 \pm 19.7$ & $53.7 \pm 11.9 *$ & $65.0 \pm 26.0$ & $46.5 \pm 21.2$ & $40.8 \pm 15.9 \#$ \\
\hline TC/HDL-C ratio & $3.0 \pm 0.65$ & $2.3 \pm 0.39 *$ & $3.5 \pm 2.0$ & $2.6 \pm 1.1$ & $2.2 \pm 0.77$ \\
\hline HDL-C/(LDL-C + VLDL-C) ratio & $0.57 \pm 0.22$ & $0.87 \pm 0.25 *$ & $0.61 \pm 0.39$ & $0.81 \pm 0.33$ & $1.2 \pm 0.7 \#$ \\
\hline Triglyceride (mg/dL) & $51.5 \pm 13.5$ & $54.9 \pm 11.1$ & $39.5 \pm 9.7$ & $40.3 \pm 12.7$ & $52.4 \pm 19.7$ \\
\hline $\begin{array}{l}\text { Atherogenic index } \\
11 \text { weeks }\end{array}$ & $1.81 \pm 0.44$ & $1.26 \pm 0.56$ & $2.06 \pm 0.39$ & $1.54 \pm 0.57$ & $0.94 \pm 0.47 \#$ \\
\hline Total cholesterol (mg/dL) & $121.9 \pm 21.2$ & $90.1 \pm 18.1 *$ & $110.4 \pm 31.2$ & $100.4 \pm 36.0$ & $80.6 \pm 20.1 \#$ \\
\hline HDL-C $(\mathrm{mg} / \mathrm{dL})$ & $36.0 \pm 10.9$ & $45.8 \pm 6.0 *$ & $33.3 \pm 9.8$ & $40.5 \pm 13.5$ & $44.9 \pm 9.8 \#$ \\
\hline LDL-C (mg/dL) & $49.1 \pm 22.0$ & $15.0 \pm 4.0 *$ & $45.6 \pm 29.1$ & $37.3 \pm 27.8$ & $12.1 \pm 6.6 \# @$ \\
\hline VLDL-C (mg/dL) & $36.7 \pm 9.1$ & $29.3 \pm 9.7$ & $31.5 \pm 6.5$ & $22.5 \pm 7.2 \#$ & $23.7 \pm 11.5$ \\
\hline LDL-C + VLDL-C & $85.8 \pm 25.3$ & $44.3 \pm 16.6^{*}$ & $77.1 \pm 30.8$ & $59.8 \pm 28.0$ & $35.8 \pm 20.8 \#$ \\
\hline TC/HDL-C ratio & $3.8 \pm 1.8$ & $2.0 \pm 0.30 *$ & $3.6 \pm 1.4$ & $2.5 \pm 0.63$ & $1.9 \pm 0.59 \#$ \\
\hline HDL-C/(LDL-C + VLDL-C) ratio & $0.47 \pm 0.25$ & $1.1 \pm 0.4$ * & $0.53 \pm 0.36$ & $0.78 \pm 0.37$ & $1.8 \pm 1.4 \#$ \\
\hline Triglyceride $(\mathrm{mg} / \mathrm{dL})$ & $39.4 \pm 12.4$ & $58.2 \pm 19.7 *$ & $50.5 \pm 13.7$ & $31.0 \pm 29.3$ & $69.7 \pm 14.9$ \#@ \\
\hline Atherogenic index & $1.93 \pm 0.49$ & $0.94 \pm 0.67 *$ & $2.25 \pm 0.58$ & $1.51 \pm 0.71 \#$ & $0.84 \pm 0.43 \# @$ \\
\hline
\end{tabular}

Results are expressed as mean \pm SD for each group $(\mathrm{n}=8)$. The significant difference $(p<0.05)$ was analyzed by one-way ANOVA and two-tailed Student's t-test. *: versus C; \#: versus DM; \&: versus CS; @: versus DM + TZD. C: control diet; CS: control diet $+5 \%$ high molecular weight chitosan; DM: diabetes + control diet; DM + TZD: diabetes + control diet + $0.8 \mathrm{mg} / \mathrm{kg}$ thiazolidinediones (rosiglitazone); $\mathrm{DM}+\mathrm{CS}$ : diabetes + control diet $+5 \%$ high molecular weight chitosan .

Table 5. The changes of hepatic lipid profiles in SD rats fed different experimental diets for 6 and 11 weeks.

\begin{tabular}{cccccc}
\hline Diet & C & CS & DM & DM + TZD & DM + CS \\
\hline 6 weeks & & & & & \\
Total cholesterol (mg/g liver) & $53.7 \pm 11.4$ & $34.5 \pm 5.2^{*}$ & $59.5 \pm 15.2$ & $45.0 \pm 10.7 \#$ & $35.9 \pm 9.9 \#$ \\
Triglyceride (mg/g liver) & $45.4 \pm 11.4$ & $35.6 \pm 6.2$ & $59.4 \pm 18.2$ & $42.8 \pm 12.4$ & $43.7 \pm 12.1$ \\
$\mathbf{1 1}$ weeks & & & & & \\
Total cholesterol (mg/g liver) & $89.5 \pm 24.8$ & $57.1 \pm 12.7 *$ & $116.4 \pm 15.7 *$ & $101.2 \pm 12.2$ & $45.8 \pm 13.2 \# @$ \\
Triglyceride (mg/g liver) & $63.5 \pm 12.3$ & $58.5 \pm 9.5$ & $79.4 \pm 23.8$ & $52.5 \pm 13.4 \#$ & $71.7 \pm 17.5$ \\
\hline
\end{tabular}

Results are expressed as mean \pm SD for each group $(n=8)$. The significant difference $(p<0.05)$ was analyzed by one-way ANOVA and twotailed Student's $t$-test. *: versus C; \#: versus DM; @: versus DM + TZD. C: control diet; CS: control diet + 5\% high molecular weight chitosan; DM: diabetes + control diet; DM + TZD: diabetes + control diet $+0.8 \mathrm{mg} / \mathrm{kg}$ thiazolidinediones (rosiglitazone); DM + CS: diabetes + control diet $+5 \%$ high molecular weight chitosan.

Moreover, the fecal weights and levels of fecal total cholesterol and triglyceride were significantly increased in CS (versus C) and DM + CS (versus DM) groups at both 6- and 11week feeding duration (Table 6). There were significant increases in fecal total cholesterol levels (mg/day) in the 6-week feeding duration group and fecal total cholesterol and triglyceride levels (mg/g feces; $\mathrm{mg} /$ day) in the 11-week feeding duration groups in the $\mathrm{DM}+\mathrm{CS}$ group compared to DM + TZD group (Table 6). 
Table 6. The changes of fecal weight, total cholesterol, and triglyceride levels in SD rats fed different experimental diets for 6 and 11 weeks.

\begin{tabular}{|c|c|c|c|c|c|}
\hline Diet & $\mathrm{C}$ & CS & DM & DM + TZD & $\mathrm{DM}+\mathrm{CS}$ \\
\hline \multicolumn{6}{|l|}{6 weeks } \\
\hline Feces wet weight (g/day) & $1.9 \pm 0.34$ & $2.4 \pm 0.37 *$ & $2.0 \pm 0.43$ & $2.1 \pm 0.18$ & $2.7 \pm 0.57 \#$ \\
\hline Feces dry weight (g/day) & $1.7 \pm 0.27$ & $2.1 \pm 0.34$ * & $1.7 \pm 0.32$ & $1.9 \pm 0.15$ & $2.2 \pm 0.35 \#$ \\
\hline \multicolumn{6}{|l|}{ Total cholesterol } \\
\hline (mg/g feces) & $17.1 \pm 3.4$ & $31.4 \pm 8.4^{*}$ & $17.6 \pm 6.5$ & $17.7 \pm 3.0$ & $31.4 \pm 6.6 \#$ \\
\hline (mg/day) & $28.5 \pm 7.3$ & $64.0 \pm 17.8^{*}$ & $31.4 \pm 15.2$ & $34.0 \pm 7.0$ & $67.6 \pm 11.3$ \#@ \\
\hline \multicolumn{6}{|l|}{ Triglyceride } \\
\hline (mg/g feces) & $3.4 \pm 0.35$ & $5.1 \pm 1.3 *$ & $4.3 \pm 0.83$ & $4.9 \pm 1.1$ & $6.5 \pm 1.4 \#$ \\
\hline (mg/day) & $5.7 \pm 1.3$ & $10.4 \pm 2.8 *$ & $7.6 \pm 2.4$ & $9.2 \pm 1.6$ & $14.0 \pm 2.4 \# \&$ \\
\hline \multicolumn{6}{|l|}{11 weeks } \\
\hline Feces wet weight (g/day) & $1.6 \pm 0.24$ & $3.2 \pm 0.61 *$ & $1.6 \pm 0.34$ & $1.9 \pm 0.36$ & $2.9 \pm 0.61 \#$ \\
\hline Feces dry weight (g/day) & $1.1 \pm 0.26$ & $2.7 \pm 0.63 *$ & $1.1 \pm 0.31$ & $1.5 \pm 0.36$ & $2.3 \pm 0.69 \#$ \\
\hline \multicolumn{6}{|l|}{ Total cholesterol } \\
\hline (mg/g feces) & $24.3 \pm 6.6$ & $31.7 \pm 7.1 *$ & $20.2 \pm 5.0$ & $19.8 \pm 5.8$ & $29.3 \pm 6.2 \# @$ \\
\hline (mg/day) & $26.9 \pm 11.3$ & $86.6 \pm 27.1^{*}$ & $23.4 \pm 10.5$ & $29.3 \pm 12.5$ & $69.0 \pm 28.3 \# @$ \\
\hline \multicolumn{6}{|l|}{ Triglyceride } \\
\hline (mg/g feces) & $10.9 \pm 1.5$ & $15.0 \pm 3.0 *$ & $12.2 \pm 2.3$ & $12.8 \pm 3.6$ & $15.9 \pm 3.3$ \#@ \\
\hline (mg/day) & $12.0 \pm 3.5$ & $41.0 \pm 11.6^{*}$ & $13.5 \pm 3.5$ & $18.5 \pm 5.7$ & $36.5 \pm 12.3$ \#@ \\
\hline
\end{tabular}

Results are expressed as mean \pm SD for each group $(n=8)$. The significant difference $(p<0.05)$ was analyzed by one-way ANOVA and twotailed Student's $t$-test. *: versus C; \#: versus DM; \&: versus CS; @: versus DM + TZD. C: control diet; CS: control diet + 5\% high molecular weight chitosan; DM: diabetes + control diet; DM + TZD: diabetes + control diet $+0.8 \mathrm{mg} / \mathrm{kg}$ thiazolidinediones; DM + CS: diabetes + control diet $+5 \%$ high molecular weight chitosan.

2.4. Effects of Chitosan on Metabolic Signaling Proteins in Liver, Plasma and Small Intestine and Enzyme Activities in Adipose Tissue in Diabetic Rats with Different Feeding Duration

We next explored the influence of chitosan feeding duration on metabolic signaling proteins in the liver, plasma, and small intestine enzyme activities in adipose tissue in diabetic rats. As shown in Figures 1 and 2, the levels of protein expression in the livers for phosphorylated AMP-activated protein kinase (AMPK) (pAMPK/AMPK ratio), peroxisome proliferator-activated receptor (PPAR) $\alpha$, and microsomal triglyceride transfer proteins (MTTP) were significantly increased, and for PPAR $\gamma$ and sterol regulatory element binding protein (SREBP)-1c were significantly decreased in CS (versus C) and DM + CS (versus DM) groups at both 6- and 11-week feeding duration. At 6-week feeding duration, in the DM + TZD group, a significant change in protein expression was observed only for the MTTP protein, which was elevated compared to the DM group; but at the 11-week feeding duration, there were increases in the pAMPK/AMPK ratio, PPAR $\gamma$, and MTTP protein expression in DM + TZD group compared to the DM group (Figures 1 and 2). There was a decrease in liver PPAR- $\gamma$ protein expression in the DM + CS group at 11-week feeding duration compared to DM + TZD group (Figure 2). Moreover, the levels of protein expression for plasma angiopoietin-like protein-4 (Angptl4) were not changed in all groups at 6-week feeding duration; but its levels could be significantly increased in CS (versus C) and DM + CS (versus DM) groups at 11-week feeding duration (Figures 3 and 4). The plasma apolipoprotein C3 (ApoCIII) and intestinal mucosal MTTP protein expression levels were significantly decreased, and the intestinal mucosal Angptl 4 protein expression levels were significantly increased in CS (versus C) and DM + CS (versus DM) groups at both 6- and 11-week feeding duration (Figures 3 and 4). There were no changes in the levels of protein expression for Angptl4, ApoCIII, and MTTP in the plasma or intestine in the DM + TZD group (versus DM) at both 6- and 11-week feeding duration (Figures 3 and 4). There was a significant decrease in intestinal MTTP protein expression in the DM + CS group at 11-week feeding duration compared to the DM + TZD group (Figure 4). 

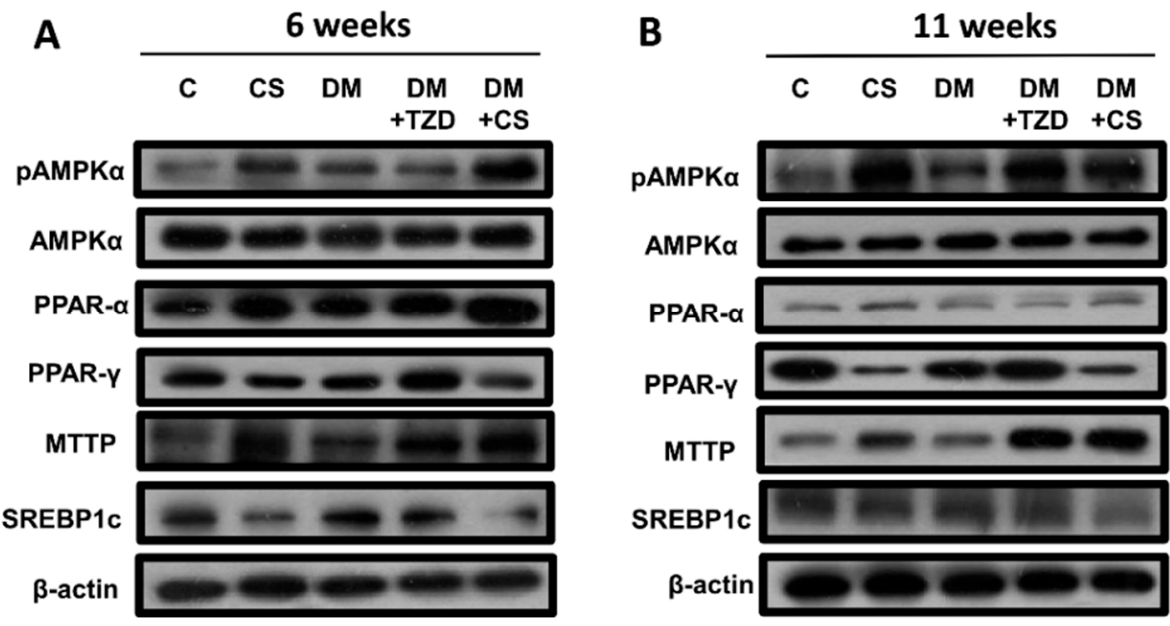

Figure 1. Effects of chitosan on metabolic signaling protein expression in the liver of diabetic rats with different feeding durations. (A) 6-week feeding duration; (B) 11-week feeding duration. The protein expressions for phosphorylated AMPK, AMPK, PPAR- $\alpha$, PPAR- $\gamma$, MTTP, SREBP1c, and $\beta$-actin (internal control) were determined by Western blot analysis. The quantification is shown in Figure 2.

A
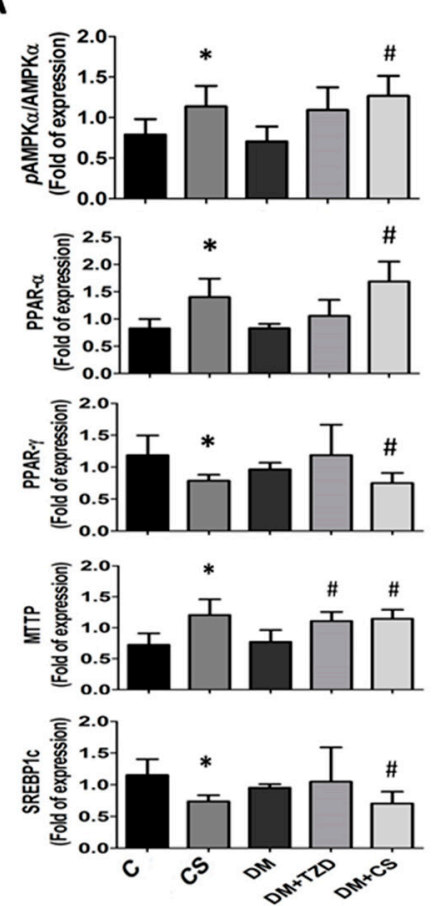

B


Figure 2. Effects of chitosan on metabolic signaling protein expression in the liver of diabetic rats with different feeding durations. (A) 6-week feeding duration; (B) 11-week feeding duration. The protein expression for phosphorylated AMPK, AMPK, PPAR- $\alpha$, PPAR- $\gamma$, MTTP, SREBP1c, and $\beta-$ actin (internal control) was determined by Western blot analysis. The densitometrical quantification is shown. Results are expressed as mean \pm S.D. for each group $(n=4-6)$. The significant difference $(p<0.05)$ were analyzed by one-way ANOVA and two-tailed Student's $t$-test. *: versus $C$; \#: versus DM; @: versus DM + TZD. 

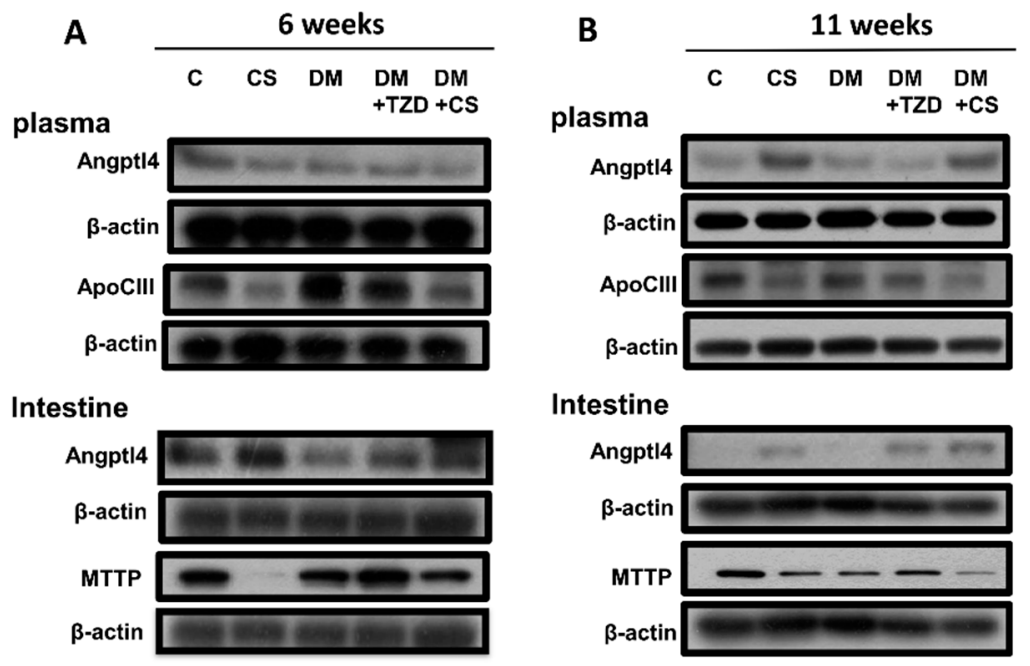

Figure 3. Effects of chitosan on metabolic signaling protein expression in the plasma and intestine of diabetic rats with different feeding durations. (A) 6-week feeding duration; (B) 11-week feeding duration. The protein expressions for Angptl4, ApoCIII, MTTP, and $\beta$-actin (internal control) were determined by Western blot analysis. The quantification is shown in Figure 4.

A plasma
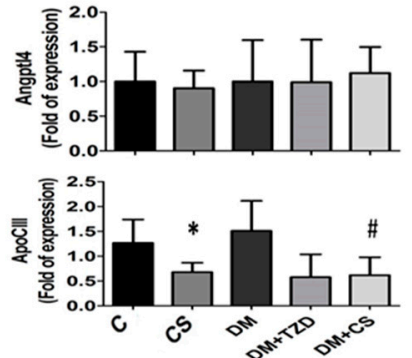

Intestine
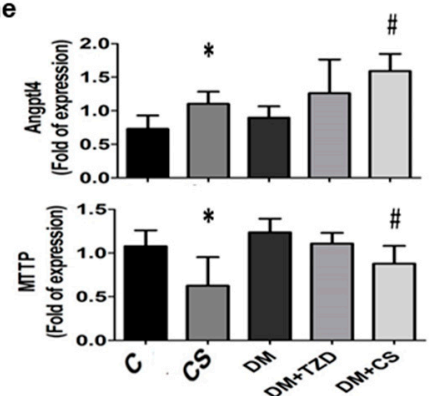

B

11 weeks

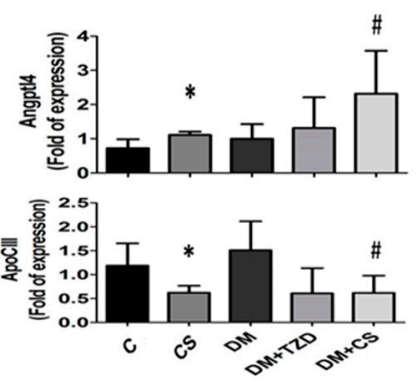

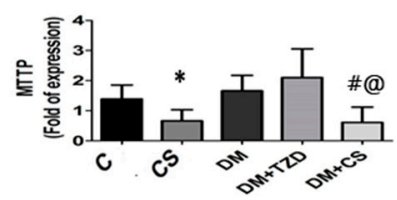

Figure 4. Effects of chitosan on metabolic signaling protein expression in the plasma and intestine of diabetic rats with different feeding durations. (A) 6-week feeding duration; (B) 11-week feeding duration. The protein expressions for Angptl4, ApoCIII, MTTP, and $\beta$-actin (internal control) were determined by Western blot analysis. The densitometrical quantification is shown. Results are expressed as mean \pm S.D. for each group $(n=4-6)$. Significant difference $(p<0.05)$ analyzed by one-way ANOVA and two-tailed Student's t-test. *: versus C; \#: versus DM; @: versus DM + TZD.

The changes of lipoprotein lipase (LPL) activity and lipolysis rate in perirenal adipose tissues were also examined. As shown in Figure 5, the LPL activity was significantly increased in both the DM + TZD and DM + CS groups compared to the DM, DM + CS, and CS groups at 6-week feeding duration; but LPL activity was significantly decreased in CS (versus C) and DM + CS (versus DM) groups, and still increased in the DM + TZD group (versus DM) at an 11-week feeding duration. There was a significant decrease in LPL 
activity in the DM + CS group at 11-week feeding duration compared to the DM + TZD group (Figure 5).

A

6 weeks

11 weeks a

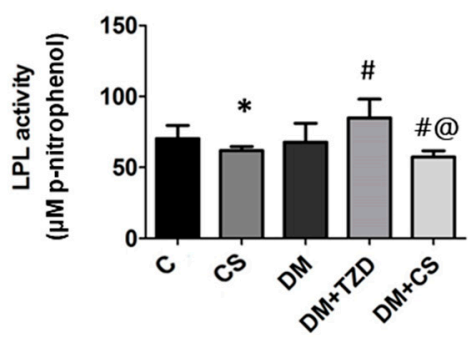

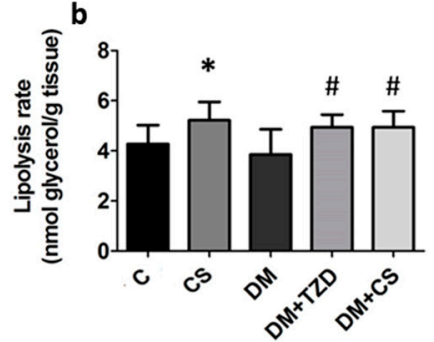

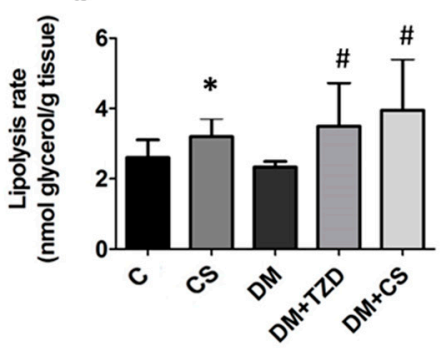

Figure 5. Effects of chitosan on LPL activity and lipolysis rate in the perirenal adipose tissue of diabetic rats with different feeding durations. (A) 6-week feeding duration; (B) 11-week feeding duration. (a) LPL activity; (b) lipolysis rate. Results are expressed as mean \pm S.D. for each group $(\mathrm{n}=8)$. Significant differences $(p<0.05)$ analyzed by one-way ANOVA and two-tailed Student's t-test. *: versus C; \#: versus DM; \&: versus CS; @: versus DM + TZD.

Moreover, the lipolysis rate was significantly increased in CS (versus C), DM + TZD (versus DM), and DM + CS (versus DM) at both 6- and 11-week feeding duration (Figure 5).

\section{Discussion}

Our previous study has shown that both low and high MW chitosan can alleviate hyperglycemia via the inhibition of liver gluconeogenesis and enhancement of skeletal muscle glucose uptake and use in an STZ-induced diabetic rat model [8]. We also found that high MW chitosan had a higher potential than low MW chitosan in reducing hypercholesterolemia and intestinal disaccharidase activity in STZ-induced diabetic rats [9]. We further found that both 5\% chitosan oligosaccharide (COS) and 5\% high MW chitosan (CS) were capable of improving lipid metabolism in an HF diet-fed rat model through different mechanisms [15]. Our previous study has also shown that CS (high MW) can reduce the plasma fructosamine, leptin, total cholesterol, and HOMA-IR more effectively than low MW chitosan in diabetic rats [13]. In the present study, we tried to confirm the beneficial effect of CS on glucose metabolism and compare the effectiveness of CS on glucose and lipid metabolism for short-term and long-term use in an STZ/nicotinamide-induced diabetic rat model. The present results showed that 11-week (long-term) CS feeding duration was more effective than 6-week (short-term) CS feeding duration in improving glucose and lipid metabolism in diabetic rats.

It has been pointed out that feeding rats with $5 \%$ chitosan does not cause changes in food intake or bodyweight in high-fat diet-fed animals [16,17]. The high-fat diet-induced obese rats fed on 5\% high molecular weight chitosan for 5-7 weeks showed no body weight change, but the liver weight and the perirenal fat weight could be significantly reduced $[18,19]$. Moreover, Hsieh et al. (2012) have found that supplementation of 5\% high molecular weight chitosan for ten weeks in streptozotocin/nicotinamide-induced diabetic rats does not change the bodyweight but significantly reduced the adipose tissue weight [20]. In the present study, we also found that $5 \%$ chitosan supplementation did 
not affect food intake or bodyweight in diabetic rats. The results of the present study are consistent with these findings.

TNF- $\alpha$ is involved in insulin resistance in obese animals and can damage insulin function, which down-regulates glucose transporter-4 (GLUT4) expression and action during glucose metabolism and enhances lipolysis [21]. Liu et al. (2010) have shown that high-molecular-weight chitosan can activate Akt (protein kinase B) to promote GLUT4 translocation in the muscle, so that blood glucose can enter cells for metabolic utilization; it can also inhibit the protein expression of phosphoenolpyruvate carboxykinase (PEPCK) and phosphorylated p38 MAPK and increase the phosphorylated AMPK in the liver, indicating that chitosan can inhibit liver gluconeogenesis and enhance skeletal muscle glucose uptake to improve hyperglycemia [8]. In the present study, the 6-week trials showed that the TNF- $\alpha$ concentration did not change significantly in diabetic rats with or without chitosan supplementation. However, in the 11-week trials, the concentrations of TNF- $\alpha$ in diabetic rats were significantly increased, which could be effectively reversed by TZD treatment and chitosan supplementation. Chitosan supplementation could also reduce insulin levels. These results indicate that chitosan supplementation alleviates insulin resistance and regulates insulin secretion, further improving blood glucose levels.

AMPK is an important regulator of metabolism, which can improve energy imbalance by metabolic stress [22]. AMPK can trigger lipid oxidation, increase lipid utilization, and inhibit lipid synthesis and adipocyte differentiation in the liver [22-24]. PPAR $\alpha$ plays an important role in the gene regulation of lipid metabolism [25]. Studies have shown that PPAR $\alpha$ activation in obese and insulin-resistant animal models can effectively stimulate fatty acid oxidation and inhibit the lipid accumulation in liver and muscle tissues, improving insulin sensitivity and insulin resistance [26,27]. PPAR $\gamma$ in the liver plays a role in regulating the homeostasis of triglyceride, leading to hepatic steatosis, but alleviating triglyceride accumulation and insulin resistance in other tissues [28]. In the present study, at both 6- and 11-week feeding duration, the protein expression levels of phosphorylated AMPK and PPAR $\alpha$ were significantly increased in the livers of CS and DM + CS groups. In addition, chitosan supplementation could also reduce the protein expression levels of PPAR $\gamma$ and SREBP1c in the livers. These results suggest that chitosan supplementation has the ability to adjust lipid metabolism-related signaling pathways during diabetic conditioning, even in the early stage.

Angiopoietin-like proteins (Angptls) inhibit the activity of LPL, reducing the clearance rate of VLDL [29]. Apo CIII can also regulate LPL activity and control the clearance of VLDL [30]. MTTP exists in cellular microsomes and endoplasmic reticulum and is a lipid transport protein necessary for the synthesis and secretion of VLDL in the liver and chylomicrons in the intestine; MTTP can promote the transport of triglyceride, cholesterol, and phospholipid on both sides of the membrane [31]. In the present study, we found that in the CS and DM + CS groups, the expression of MTTP protein in the liver could be significantly increased, which might increase the release of liver lipids into the blood. Moreover, chitosan supplementation could also reduce the concentration of TNF- $\alpha$, which might improve insulin resistance, thereby reducing insulin secretion. Yamada et al. (2006) have indicated that insulin can downregulate the expression of Angpt14 in adipocytes [32]. Sukonina et al. (2006) have also reported that the increase of Angptl4 expression can convert the active LPL dimer to an inactive LPL monomer in adipose tissue [33]. Therefore, we speculated that chitosan supplementation reduced the TNF- $\alpha$ level and the insulin secretion after an 11-week feeding, which caused the increase of plasma Angptl4 protein expression and the decrease of LPL activity in the adipose tissue, leading to the increase of plasma triglyceride levels. Gallaher et al. (2002) have also shown that chitosan supplementation can increase plasma triglycerides in normal and diabetic rats [34].

Chiu et al. (2015) have shown that supplementation of 5\% and 7\% chitosan can increase the expression of MTTP and Apo E and improve the accumulation of lipids in the liver [18]. It has been found that the reduction of Angptl4 expression in the intestine increases pancreatic lipase activity, which can regulate lipid digestion [35]. Studies have 
shown that in animal models of diabetes or insulin resistance, the MTTP mRNA expression and activity in the intestine are increased, and the content of triglycerides in chylomicrons are increased [36-38]. In the present study, we found that chitosan supplementation at both 6- and 11-week feeding durations could improve the accumulation of lipids in the livers of diabetic rats by increasing the protein expression of liver MTTP and inhibit intestinal lipid digestion and absorption capacity by increasing the intestinal Angptl4 protein expression and by decreasing the intestinal MTTP protein expression.

\section{Materials and Methods}

\subsection{Animals and Experimental Diets}

Six-week-old male Sprague-Dawley (SD) rats were purchased from BioLASCO Taiwan Co., Ltd. (Taipei, Taiwan). Rats were housed in cages in the animal room and fed the normal chow diet (Laboratory Rodent Diet 5001, St. Louis, MO, USA) for one week. The temperature of the animal room was maintained at $23 \pm 1{ }^{\circ} \mathrm{C}$, the humidity was $40-60 \%$, and the light was controlled for a $12 \mathrm{~h}$ light/dark cycle. Food and water were given ad libitum. Rats were randomly divided into five groups ( $n=8 /$ group): (1) control (C), (2) control + 5\% chitosan (CS), (3) diabetes (DM), (4) diabetes $+0.8 \mathrm{mg} / \mathrm{kg}$ TZD (rosiglitazone, p.o.) (DM + TZD), and (5) diabetes $+5 \%$ chitosan $(\mathrm{DM}+\mathrm{CS})$. For induction of diabetes, nicotinamide $(230 \mathrm{mg} / \mathrm{kg})$ and streptozotocin $(65 \mathrm{mg} / \mathrm{kg}$ in $0.1 \mathrm{M}$ sodium citrate, $\mathrm{pH} 4$.5) were subcutaneously injected into rats, and blood glucose tests were performed one week after induction to determine whether hyperglycemia was induced. The non-diabetic control rats were subcutaneously injected by vehicle $(0.5 \mathrm{~mL}$ of sodium citrate buffer). The first two groups were non-diabetic groups, and the last three groups were diabetic groups, and they were fed the different experimental diets (the formulation was shown in Table 7) for 6 or 11 weeks. The body weight and food consumption of all groups were measured weekly until euthanasia. Feed efficiency was calculated by [weight gain $(\mathrm{g}) /$ food intake $(\mathrm{g})] \times 100 \%$. This animal study was approved by the Animal House Management Committee of the National Taiwan Ocean University (permission number: 104033). The experimental procedures were in accordance with the Guide for the Care and Use of Laboratory Animals [39]. The determination of the experimental dosage and time course was based on the results of our preliminary tests.

Table 7. Composition of experimental diets (\%).

\begin{tabular}{cccccc}
\hline Ingredient (\%) & C & CS & DM & DM + TZD & DM + CS \\
\hline Casein & 20 & 20 & 20 & 20 & 20 \\
Lard & 15 & 15 & 15 & 15 & 15 \\
Soybean oil & 2 & 2 & 2 & 2 & 2 \\
Vitamin & 1 & 1 & 1 & 1 & 1 \\
mixture & ${ }^{1}$ & 4 & 4 & 4 & 4 \\
Salt mixture & & 4 & 0.5 & 0.5 & 0.5 \\
Cholesterol & 0.5 & 0.5 & 0.2 & 0.2 & 0.2 \\
$\quad$ Choline & 0.2 & 0.2 & 0.2 & 0.2 & 0.2 \\
chloride & 0.2 & 0.2 & 52.1 & 52.1 & 52.1 \\
Cholic acid & 52.1 & 52.1 & 5 & 5 & 5 \\
Corn starch & 5 & 5 & & &
\end{tabular}

C: control diet (15\% Lard + 2\% Soybean oil). CS: control diet (15\% Lard $+2 \%$ Soybean oil) $+5 \%$ high molecular weight chitosan. DM: diabetes + control diet (15\% Lard + 2\% Soybean oil). DM + TZD: diabetes + control diet $(15 \%$ Lard $+2 \%$ Soybean oil $)+0.8 \mathrm{mg} / \mathrm{kg}$ thiazolidinediones. DM + CS: diabetes + control diet $(15 \%$ Lard $+2 \%$ Soybean oil $)+5 \%$ high molecular weight chitosan. ${ }^{1}$ AIN-93 vitamin mixture. ${ }^{2}$ AIN-93 mineral mixture. ${ }^{3}$ The average MW and DD of chitosan about $6 \times 10^{5}$ Dalton and $87 \%$, respectively.

High molecular weight (MW) chitosan was purchased from Koyo Chemical Co. (Tokyo, Japan). The average MW and degree of deacetylation (DD) of chitosan are about 
$6 \times 10^{5}$ Dalton and $87 \%$, respectively. Thiazolidinediones-rosiglitazone was obtained from Sigma-Aldrich (St. Louis, MO, USA).

\subsection{Sampling for Blood, Tissues, and Feces}

Feces were collected and weighed three days before the euthanasia. The rats fasted for $12 \mathrm{~h}$ before euthanasia. Rats were euthanized with carbon dioxide. Blood samples were centrifuged at $3000 \mathrm{rpm}$ for $20 \mathrm{~min}$ in a low-speed centrifuge to collect the supernatant, which was the plasma. The liver, adipose tissue (perirenal fat and epididymal fat), and small intestine were collected and weighed. The samples of plasma, liver tissue, and feces were stored at $-80^{\circ} \mathrm{C}$ until further analysis.

\subsection{Detection of Triglyceride (TG), Total Cholesterol (TC), and Lipoproteins}

The extraction of lipids in the liver and feces was performed as previously described [40]. Briefly, $0.2 \mathrm{~g}$ liver or feces in chloroform and methanol mixed solution $(2: 1, v / v)$ were homogenized by a homogenizer and then centrifuged at $1750 \times g$ for $10 \mathrm{~min}$. The supernatants were collected and stored at $-80{ }^{\circ} \mathrm{C}$ until further analysis. Both TG and TC levels in the plasma, liver, and feces were determined by enzymatic assay kits (Audit Diagnostics, Cork, Ireland) as previously described [19]. The lipoproteins (HDL, VLDL, and LDL) in the plasma were isolated by density gradient ultracentrifugation as previously described [41]. The atherogenic index in rats was measured with the formula: total cholesterol - HDL cholesterol)/HDL cholesterol [42].

\subsection{Measurement of Tumor Necrosis Factor- $\alpha$ (TNF- $\alpha$ )}

The plasma TNF- $\alpha$ levels were detected by an enzyme-linked immunosorbent assay (ELISA) kit (Assay Designs, Inc., Ann Arbor, MI, USA) for rats, as previously described [20].

4.5. Measurement of Plasma Glucose, Insulin, HOMA-IR, Aspartate Aminotransferase (AST), and Alanine Aminotransferase (ALT)

The plasma glucose was detected by a glucose assay kit (Audit Diagnostics). The plasma insulin was measured using an insulin ELISA kit for rats (Mercodia AB, Uppsala, Sweden). HOMA-IR (Homeostasis Model Assessment-Insulin Resistance) $=$ fasting insulin $(\mathrm{mU} / \mathrm{L}) \times$ fasting glucose $(\mathrm{mmol} / \mathrm{L}) / 22.5$ [43]. The plasma AST and ALT activities were determined using the AST and ALT assay kits (Randox, Antrim, UK).

\subsection{Detection of Lipolysis Rate and Lipoprotein Lipase (LPL) Activity}

Lipolysis rate was determined by the measurement of glycerol levels as described previously [15]. A glycerol detection kit (Randox, Antrim, UK) was used to assay the levels of glycerol in samples. The nano-moles glycerol/gram adipose tissue/h was used to express the lipolysis rate.

LPL activity was detected by measurement of p-nitrophenol formation as described previously [15]. The absorbance at $400 \mathrm{~nm}$ was used for detection.

\subsection{Western Blotting}

The protein extraction and Western blot analysis for protein expression were determined as previously described [19]. Briefly, the proteins of samples were extracted using a radioimmunoprecipitation assay (RIPA) buffer with a cocktail of inhibitors for phosphatase and protease (Thermo Fisher Scientific, Waltham, MA, USA). The concentrations of proteins were detected by a BCA protein assay kit (Thermo Fisher Scientific). For immunoblotting, the equal protein extracts from the liver, plasma, and intestinal mucosa were separated through $8-12 \%$ sodium dodecyl sulfate-polyacrylamide electrophoresis (SDS-PAGE) gel. Then, the proteins in the gel were transferred to polyvinylidene difluoride (PVDF) membranes (Bio-Rad, Hercules, CA, USA). We blocked the PVDF membranes for $1 \mathrm{~h}$ and then incubated with primary antibodies specific for AMPK $\alpha$, phosphorylated AMPK $\alpha$ $(\mathrm{p}-\mathrm{AMPK} \alpha)($ Cell Signaling Technology, Danvers, MA, USA), Angpt14, PPAR- $\gamma$, SREBP1c, 
PPAR- $\alpha$, MTTP, ApoCIII, and $\beta$-actin (Santa Cruz Biotechnology, Santa Cruz, CA, USA) overnight. Membranes were subsequently probed with horseradish peroxidase-conjugated secondary antibodies. The reactions of antigen and antibody were determined using a Bio-Rad enhanced chemiluminescence kit (Hercules, CA, USA) and exposed to Fujifilm X-ray film (Fujifilm, Tokyo, Japan). The densitometrical quantifications of protein bands were performed by an image software (Image J 1.51; National Institutes of Health, Bethesda, MD, USA).

\subsection{Statistical Analysis}

All results are presented as the mean \pm standard deviation (S.D.). The significant differences $(p<0.05)$ among the control and treated groups were analyzed by one-way analysis of variance (ANOVA) and two-tailed Student's $t$-test with the SPSS statistical software (SPSS, 19.0, Chicago, IL, USA).

\section{Conclusions}

In this study, we demonstrated that chitosan supplementation for 11 weeks compared to 6 weeks of feeding could significantly reduce the plasma TNF- $\alpha$, insulin level, ALT activity, HOMA-IR index, and adipose tissue LPL activity. Meanwhile, it increased the plasma HDL-cholesterol level, plasma Angptl4 protein expression, and plasma triglyceride level. The plasma triglyceride levels did not change at the 6-week chitosan feeding duration but significantly increased at the 11-week chitosan feeding duration. This may be due to the decrease of plasma levels of TNF- $\alpha$ and insulin, increased plasma Angptl4 protein, and inhibition of LPL activity in adipose tissue. Moreover, chitosan supplementation could improve the lipid accumulation in the liver and enhance the fecal lipid excretion at both 6- and 11-week feeding durations. Taken together, these findings suggest that 11-week (long-term) dietary chitosan feeding may be more effective in ameliorating glucose and lipid metabolism in a NIDDM diabetic rat model compared to a 6-week feeding duration (short-term use).

Author Contributions: Conceptualization, S.-H.L. and M.-T.C.; methodology, C.-Y.C. and S.-A.F.; validation, S.-H.L., M.-T.C., C.-Y.C. and S.-A.F.; formal analysis, S.-A.F.; investigation, S.-A.F.; resources, S.-H.L. and M.-T.C.; data curation, S.-H.L., M.-T.C. and S.-A.F.; writing—original draft preparation, S.-H.L. and M.-T.C.; writing—review and editing, S.-H.L. and M.-T.C.; supervision, S.-H.L. and M.-T.C.; project administration, M.-T.C.; funding acquisition, M.-T.C. All authors have read and agreed to the published version of the manuscript.

Funding: This research was funded by the Ministry of Science and Technology, Taiwan (R.O.C.) (MOST 106-2320-B-019-004).

Institutional Review Board Statement: The study was conducted according to the guidelines of the Declaration of Helsinki and approved by the Animal House Management Committee of the National Taiwan Ocean University (protocol number: 104033; date of approval: 8 October 2015).

Data Availability Statement: The data presented in this study are available from the corresponding author upon reasonable request.

Conflicts of Interest: The authors declare no conflict of interest. The funders had no role in the design of the study; in the collection, analyses, or interpretation of data; in the writing of the manuscript, or in the decision to publish the results.

\section{References}

1. Bullard, K.M.; Cowie, C.C.; Lessem, S.E.; Saydah, S.H.; Menke, A.; Geiss, L.S.; Orchard, T.J.; Rolka, D.B.; Imperatore, G. Prevalence of diagnosed diabetes in adults by diabetes type-United States, 2016. MMWR Morb. Mortal. Wkly. Rep. 2018, 67, 359-361. [CrossRef]

2. World Health Organization. Fact Sheet: Diabetes. Available online: https://www.who.int/news-room/fact-sheets/detail/ diabetes (accessed on 28 July 2021).

3. Vaughan, D.E. PAI-1 and atherothrombosis. J. Thromb. Haemost. 2005, 3, 1879-1883. [CrossRef] [PubMed] 
4. Hotamisligil, G.S.; Peraldi, P.; Budavari, A.; Ellis, R.; White, M.F.; Spiegelman, B.M. IRS-1-Mediated Inhibition of Insulin Receptor Tyrosine Kinase Activity in TNF-alpha- and Obesity-Induced Insulin Resistance. Science 1996, 271, 665-670. [CrossRef] [PubMed]

5. Gallaher, C.M.; Munion, J.; Hesslink, R.; Wise, J.; Gallaher, D.D. Cholesterol reduction by glucomannan and chitosan is mediated by changes in cholesterol absorption and bile acid and fat excretion in rats. J. Nutr. 2000, 130, 2753-2759. [CrossRef] [PubMed]

6. Yao, H.-T.; Chiang, M.-T. Effect of chitosan on plasma lipids, hepatic lipids, and fecal bile acid in hamsters. J. Food Drug Anal. 2006, 14, 6. [CrossRef]

7. Liu, J.; Zhang, J.; Xia, W. Hypocholesterolaemic effects of different chitosan samples in vitro and in vivo. Food Chem. 2008, 107, 419-425. [CrossRef]

8. Liu, S.-H.; Chang, Y.-H.; Chiang, M.-T. Chitosan Reduces Gluconeogenesis and Increases Glucose Uptake in Skeletal Muscle in Streptozotocin-Induced Diabetic Rats. J. Agric. Food Chem. 2010, 58, 5795-5800. [CrossRef]

9. Yao, H.-T.; Huang, S.-Y.; Chiang, M.-T. A comparative study on hypoglycemic and hypocholesterolemic effects of high and low molecular weight chitosan in streptozotocin-induced diabetic rats. Food Chem. Toxicol. 2008, 46, 1525-1534. [CrossRef]

10. Neyrinck, A.M.; Bindels, L.B.; De Backer, F.; Pachikian, B.D.; Cani, P.D.; Delzenne, N.M. Dietary supplementation with chi-tosan derived from mushrooms changes adipocytokine profile in diet-induced obese mice, a phenomenon linked to its lipid-lowering action. Int. Immunopharmacol. 2009, 9, 767-773. [CrossRef]

11. Yao, H.-T.; Chiang, M.-T. Plasma Lipoprotein Cholesterol in Rats Fed a Diet Enriched in Chitosan and Cholesterol. J. Nutr. Sci. Vitaminol. 2002, 48, 379-383. [CrossRef] [PubMed]

12. Guo, W.; Yi, L.; Zhou, B.; Li, M. Chitosan modifies glycemic levels in people with metabolic syndrome and related disorders: Meta-analysis with trial sequential analysis. Nutr. J. 2020, 19, 1-13. [CrossRef] [PubMed]

13. Chang, H.P.; Yao, H.T.; Chiang, M.T. Effects of high and low molecular chitosan on plasma cholesterol, glucose and adipocytokines in diabetic rats induced by streptozotocin and nicotinamide. J. Food Drug Anal. 2012, 20, 661-667.

14. Masiello, P.; Broca, C.; Gross, R.; Roye, M.; Manteghetti, M.; Hillaire-Buys, D.; Novelli, M.; Ribes, G. Experimental NIDDM: Development of a new model in adult rats administered streptozotocin and nicotinamide. Diabetes 1998, 47, 224-229. [CrossRef]

15. Liu, S.H.; Chen, R.Y.; Chiang, M.T. Effects and mechanisms of chitosan and chitosan oligosaccharide on hepatic lipogenesis and lipid peroxidation, adipose lipolysis, and intestinal lipid absorption in rats with high-fat diet-induced obesity. Int. J. Mol. Sci. 2021, 22, 1139. [CrossRef]

16. Chiang, M.-T.; Yao, H.-T.; Chen, H.-C. Effect of Dietary Chitosans with Different Viscosity on Plasma Lipids and Lipid Peroxidation in Rats Fed on A Diet Enriched with Cholesterol. Biosci. Biotechnol. Biochem. 2000, 64, 965-971. [CrossRef] [PubMed]

17. Sugano, M.; Fujikawa, T.; Hiratsuji, Y.; Nakashima, K.; Fukuda, N.; Hasegawa, Y. A novel use of chitosan as a hypocholes-terolemic agent in rats. Am. J. Clin. Nutr. 1980, 33, 787-793. [CrossRef]

18. Chiu, C.Y.; Chan, I.L.; Yang, T.H.; Liu, S.H.; Chiang, M.T. Supplementation of chitosan alleviates high-fat diet-enhanced lipogenesis in rats via adenosine monophosphate (AMP)-activated protein kinase activation and inhibition of lipogenesis-associated genes. $J$. Agric. Food Chem. 2015, 63, 2979-2988. [CrossRef] [PubMed]

19. Chiu, C.-Y.; Chang, T.-C.; Liu, S.-H.; Chiang, M.-T. The regulatory effects of fish oil and chitosan on hepatic lipogenic signals in high-fat diet-induced obese rats. J. Food Drug Anal. 2017, 25, 919-930. [CrossRef] [PubMed]

20. Hsieh, Y.-L.; Yao, H.-T.; Cheng, R.-S.; Chiang, M.-T. Chitosan Reduces Plasma Adipocytokines and Lipid Accumulation in Liver and Adipose Tissues and Ameliorates Insulin Resistance in Diabetic Rats. J. Med. Food 2012, 15, 453-460. [CrossRef] [PubMed]

21. Schinner, S.; Scherbaum, W.A.; Bornstein, S.R.; Barthel, A. Molecular mechanisms of insulin resistance. Diabet. Med. 2005, 22, 674-682. [CrossRef] [PubMed]

22. Garcia, D.; Shaw, R.J. AMPK: Mechanisms of Cellular Energy Sensing and Restoration of Metabolic Balance. Mol. Cell 2017, 66, 789-800. [CrossRef] [PubMed]

23. Towler, M.C.; Hardie, D.G. AMP-activated protein kinase in metabolic control and insulin signaling. Circ. Res. 2007, 100, 328-341. [CrossRef]

24. Lage, R.; Diéguez, C.; Vidal-Puig, A.; López, M. AMPK: A metabolic gauge regulating whole-body energy homeostasis. Trends Mol. Med. 2008, 14, 539-549. [CrossRef] [PubMed]

25. Schoonjans, K.; Staels, B.; Auwerx, J. The peroxisome proliferator activated receptors (PPARs) and their effects on lipid metabolism and adipocyte differentiation. Biochim. Biophys. Acta 1996, 1302, 93-109. [CrossRef]

26. Ide, T.; Nakazawa, T.; Mochizuki, T.; Murakami, K. Tissue-specifi c actions of antidiabetic thiazolidinediones on the reduced fatty acid oxidation in skeletal muscle and liver of Zucker diabetic fatty rats. Metabolism 2000, 49, 521-525. [CrossRef]

27. Jeong, S.; Yoon, M. Fenofibrate inhibits adipocyte hypertrophy and insulin resistance by activating adipose PPAR $\alpha$ in high fat diet-induced obese mice. Exp. Mol. Med. 2009, 41, 397-405. [CrossRef] [PubMed]

28. Gavrilova, O.; Haluzik, M.; Matsusue, K.; Cutson, J.J.; Johnson, L.; Dietz, K.R.; Nicol, C.J.; Vinson, C.; Gonzalez, F.J.; Reitman, M.L. Liver peroxisome proliferator-activated receptor gamma contributes to hepatic steatosis, triglyceride clearance, and reg-ulation of body fat mass. J. Biol. Chem. 2003, 278, 34268-34276. [CrossRef]

29. Dijk, W.; Kersten, S. Regulation of lipoprotein lipase by Angptl4. Trends Endocrinol. Metab. 2014, 25, 146-155. [CrossRef] [PubMed]

30. Wang, C.S.; McConathy, W.J.; Kloer, H.U.; Alaupovic, P. Modulation of lipoprotein lipase activity by apolipoproteins. Effect of apolipoprotein C-III. J. Clin. Investig. 1985, 75, 384-390. [CrossRef]

31. Liu, L.; Ouyang, D. Function and clinical significance of microsomal triglyceride transfer protein. Int. J. Clin. Exp. Pathol. 2009, 29, 152-154. 
32. Yamada, T.; Ozaki, N.; Kato, Y.; Miura, Y.; Oiso, Y. Insulin downregulates angiopoietin-like protein 4 mRNA in 3T3-L1 adi-pocytes. Biochem. Biophys. Res. Commun. 2006, 347, 1138-1144. [CrossRef]

33. Sukonina, V.; Lookene, A.; Olivecrona, T. Angiopoietin-like protein 4 converts lipoprotein lipase to inactive monomers and modulates lipase activity in adipose tissue. Proc. Natl. Acad. Sci. USA 2006, 103, 17450-17455. [CrossRef] [PubMed]

34. Gallaher, D.D.; Gallaher, C.M.; Mahrt, G.J.; Carr, T.P.; Hollingshead, C.H.; Hesslink, R.; Wise, J. A Glucomannan and Chitosan Fiber Supplement Decreases Plasma Cholesterol and Increases Cholesterol Excretion in Overweight Normocholesterolemic Humans. J. Am. Coll. Nutr. 2002, 21, 428-433. [CrossRef]

35. Mattijssen, F.; Alex, S.; Swarts, H.J.; Groen, A.K.; van Schothorst, E.M.; Kersten, S. Angptl4 serves as an endogenous inhibitor of intestinal lipid digestion. Mol. Metab. 2013, 3, 135-144. [CrossRef]

36. Gleeson, A.; Anderton, K.; Owens, D.; Bennett, A.; Collins, P.; Johnson, A.; White, D.; Tomkin, G.H. The Role of microsomal triglyceride transfer protein and dietary cholesterol in chylomicron production in diabetes. Diabetologia 1999, 42, 944-948. [CrossRef] [PubMed]

37. Phillips, C.; Bennett, A.; Anderton, K.; Owens, D.; Collins, P.; White, D.; Tomkin, G.H. Intestinal rather than hepatic micro-somal triglyceride transfer protein as a cause of postprandial dyslipidemia in diabetes. Metabolism 2002, 51, 847-852. [CrossRef] [PubMed]

38. Phillips, C.; Owens, D.; Collins, P.; Tomkin, G.H. Microsomal triglyceride transfer protein: Does insulin resistance play a role in the regulation of chylomicron assembly? Atherosclerosis 2002, 160, 355-360. [CrossRef]

39. Institute of Laboratory Animal Resources. Guide for the Care and Use of Laboratory Animals; National Academy Press: Washington, DC, USA, 2011.

40. Folch, J.; Lees, M.; Stanley, G.S. A simple method for the isolation and purification of total lipides from animal tissues. J. Biol. Chem. 1957, 226, 497-509. [CrossRef]

41. Takehisa, F.; Suzuki, Y. Effect of guar gum and cholestyramine on plasma lipoprotein cholesterol in rats. J. Jpn. Soc. Food Sci. 1990, 43, 269-274. [CrossRef]

42. Yokozawa, T.; Cho, E.J.; Sasaki, S.; Satoh, A.; Okamoto, T.; Sei, Y. The Protective Role of Chinese Prescription Kangen-karyu Extract on Diet-Induced Hypercholesterolemia in Rats. Biol. Pharm. Bull. 2006, 29, 760-765. [CrossRef]

43. Matthews, D.R.; Hosker, J.P.; Rudenski, A.S.; Naylor, B.A.; Treacher, D.F.; Turner, R.C. Homeostasis model assessment: Insulin resistance and beta-cell function from fasting plasma glucose and insulin concentrations in man. Diabetologia 1985, 28, 412-419. [CrossRef] [PubMed] 